\section{О некоторых проблемах развития рекреационного направления в Карелии}

Романов Г.Е.।

Протасова А.В.

Петрозаводский государственньй университет

Обладание ресурсом не делает собственника богаче. Только его использование способствует росту благосостояния. Рекреация - это и ресурс , и одно из направлений использования территорий. Оно становится все более популярным. Но как заставить его работать, приносить доход, снимать многие проблемы, стоящие перед регионами?

Ключевые слова: многочелевое природопользование. рекреачия, спрос и предложение.

\section{ВВЕДЕНИЕ}

Карелия располагает уникальными природными ландшафтами. Под ландшафтами понимают такую генетически однородную территорию, на которой наблюдается закономерное и типическое повторение одних и тех же взаимосвязанных сочетаний: геологического строения, форм рельефа, поверхностных и подземных вод; микроклиматов, почвенных растений, фито- и зооценозов. По существующей шкале оценки ландшафтов примерно $50 \%$ территории Карелии имеет высокую и очень высокую оценку рекреационных достоинств. Однако по-прежнему практически единственным ресурсом, который заготавливают лесные предприятия, остается древесина. Это имеет глубокие исторические корни и характерно для многих стран. Они прошли путь от полного отрицания значимости восстановительной функции леса, "побочных" лесных продуктов в жизни человека до их широкого применения, что позволяет им получать ныне дополнительный доход, в несколько раз превышающий сумму средств от реализации древесины. Карелия делает только первые шаги в данном направлении

\section{ОБСУЖДЕНИЕ}

Насаждение, как неотъемлемая часть ландшафта, представляет единую, со своими особенностями, многокомпонентную экологическую систему. Она обеспечивает человека широким ассортиментом ресурсов экономического, социального и природного значения. Но его признание как носителя широкого ассортимента ресурсов пришло не сразу. Хотя первый акт, предусматривающий многоцелевое природопользование, относится к середине XVП века, вплоть до XX века леса использовались для нужд сельского хозяйства, отопления и строительства [5]. В Финляндии, например, древесная составляющая лесов была един-

I Aвторы, соответственно, доцент кафедры лесного хозяйства и студентка лесоинженерного факультета (c) Г.Е.Романов, А.В.Протасова, 1996 ственной до 60-х годов [3], когда вышла первая научная статья, сформулировавшая основные идеи многоцелевого природопользования. Но только к концу 70 годов это направление в Финляндии и в других странах Европы воплотилось в государственную политику.

Что такое многоцелевое природопользование? Эту философию управления территорией мы сформулировали так.

Если на какой-то территории имеется несколько ресурсов - объедини их; когда располагаешь только одним - предложи потребителю что-то еще, например, сервисные услуги. Задержи его на заранее подготовленном объекте с тем, чтобы получить с него больший доход и уменьшить отрицательное воздействие на необустроенную территорию.

Таким образом, многоцелевое природопользование выступает как комплекс мероприятий, соединяющий разнонаправленные цели при организации работ в различных типах леса или природных объектах, но объединенных общей целью - поиском удовлетворительного взаимоотношения природной, социальной и экономической составляющих предприятия или района при их использовании в настоящее время и на перспективу. Это требует перейти от биогеоценоза к ландшафту $[1,2]$. Объектом хозяйствования становится не таксационный выдел, а природная система, объединяющая совокупность типов леса, все многообразие природных ресурсов.

Организация производства. выбор направления развития района связаны с наличием потребности, спроса на товар, услуги. Линия DD (рис.1) характеризует спрос на товары, которые могут быть получены при переработке ресурсов, имеющихся на территории с радиусом ое. При росте цен для увеличения дохода необходимо менять форму товара, направление использования территории [4]. Изменение формы товара связано с наличием спроса на конкретные виды товаров и предполагает реализацию не сырья, а полуфабрикатов или готовой продукции; выбор направлений использования территории в зависимости от расстояния связан с изменением древесной, экологической и социальной составляющих районов по мере приближения или удаления от потребителя. Поскольку для кажцого направления возможны "свои" уровни цен, мы линию DD условно разделили на четыре части и получили ломаную линию $a b c d e$. Каждый отрезок - $a b$. $b c, c d$, de - представляет отдельное направление использования территории (см. рис.1) .

Теоретически существующие потребности позволяют сформировать ОБЩЕЕ ДЕРЕВО ЦЕЛЕЙ, которое охватило бы всю территорию Карелии. Это предполагает, что каждый район должен иметь свое направление развития. Так, предприятия, расположенные в зоне $d e$, т.е. самые удаленные, должны заготавливать древесину; $b c$ и $c d$ - развивать рекреацию, сельское хозяйство и т.п. Такое возможно при жестком планировании, когда игнорируется фактор спроса и предложения на уровне предприятия. Но нас интересует 
уровень леспромхоза (лесхоза) и даже лесопункта (лесничества), потому что плошадь лесничества (лесопункта) примерно равна плошади ландшафта; во-вторых, именно здесь объединяются все элементы экосистемы. Необходимо отметить, что на уровне любого предприятия могут быть выделены аналогичные зоны (направления), выявлен аналогичный ассортимент ресурсов, что и для любой зоны и республики в целом. Различия будут только в объемах ресурсов и их характеристиках. Но дерево целей для каждой конкретной территории (или отрезка линии abcde) должно быть свое с учетом складываюшихся потребностей. Одной из важнейших ветвей дерева целей является рекреация, и если при организации территории ее интересы не учитываются, то она часто входит в конфликт с другими элементами системы.

Рекреация в зависимости от удаленности от города предполагает три основных направления (см. рис.1):

1. Создание лесопарков в городах. Они располагаются в "социальной" зоне и предполагают пребывание рекреанта там в течение нескольких часов. Лесопарки оборудуются освещенными трассами, детскими игровыми площадками и т.п.

2. Загородные места отдыха обустраиваются в "экологической" и "социальной" зонах. В них отдыхающий может остановиться на 1-3 суток. Ему могут предложить: дома, сдаваемые в аренду, кемпинги, мотели с разным уровнем сервиса.

3. Экологический туризм - "древесная" зона. В девственных лесах прокладываются туристические маршруты продолжительностью 5-10 дней, строятся избушки, отводятся места стоянок туристов.

"Социальная", "экологическая" и "недревесная" зоны создаются в черте и вокруг населенных пунктов. Особенность Карелии заключается в том, что практически все города располагаются в районах с высокими и очень высокими рекреационными достоинствами. Однако, как уже было сказано выше, данные территории используются лесозаготовительными, горнорудными и сельскохозяйственными производствами. Рекреационное использование носит неуправляемый характер; уникальные природные ландшафты практически игнорируются. В связи с их более широким освоением мы видим несколько проблем:

1. При организации рекреационных объектов - городских парков, загородных зон отдыха, национальных парков и т.п. приходится прекращать промышленное использование территории, например, заготовку древесины. Будут меняться прежние хозяйственные связи с потребителями, в том числе и в республике. Часть из них может остаться без сырья.

2. На древесной составляющей территории воспитывалось население многих районов Карелии. Рекреация требует иного подхода, а именно - готовности служить людям, приехавшим на отдых

3. У руководства и сотрудников лесных предприятий, ориентированных прежде на потребление древесины, отсутствуют желание и умение разглядеть и поднять то, что бесхозно лежит на земле. Поэтому со стороны предприятий отсутствуют предложения широкого ассортимента товаров и услуг потенциальному потребителю. Сложно подобрать природный объект, который мог бы удовлетворить жеслким требованиям, предъявляемым рекреантами, еще сложнее обустроить его таким образом, чтобы посетитель согласился задержаться и был готов платить за предлагаемые услуги, товар.

4. Отсутствие спроса на рекреационные объекты со стороны жителей Республики Карелия вследствие неразвитости этого направления и низкой покупательной способности значительной части населения.

Рекреация, как одно из направлений многоцелевого природопользования, требует:

- - подбора природных объектов таким образом, чтобы была возможность предоставить потребителю широкий спектр услуг, ресурсов, которыми могут быть: охота, рыбалка, демонстрация народных промыслов и т.п.;

- - гибкой ценовой политики, которая, учитывая покупательную способность рекреанта, подталкивала бы его к приобретению необходимого товара, услуги. На наш взгляд, на рекреационные объекты цены должны быть установлены по соотношению спроса и предложения с учетом покупательной способности. Можно рекомендовать диверсифицированные цены с упором, особенно в период становлении предприятия, на "цены внедрения на рынок", т.е. на низкие цены;

- - воспитания нового отношения жителей районов, ориентированного на удовлетворение запроса потребителя. Мы предлагаем следующие принципы, которыми должны руководствоваться работники рекреационных объектов:

1. Доброе отношение к клиенту важнее, чем товар;

2. Отыщите потребности и удовлетворите их;

3. Производи то, что сможешь продать;

4. Сделай все, чтоб в максимальной степени возместить затраченный клиентом рубль ценностной значимостью, качеством и удовлетворенностью.

\section{ЗАКЛЮЧЕНИЕ}

Мы затронули общие вопросы, связанные с рекреацией. Но высокая социальная напряженность во многих районах Карелии требует поиска нетрадиционных подходов к решению возникших проблем. Рекреация, на наш взгляд, одно из них. При наличии спроса со стороны зарубежных и отечественных туристов появляется возможность развивать индустрию туризма в Республике. Как показал опыт многих стран, развитие этого направления позволит не только предоставлять дополнительные рабочие места, но и значительно увеличивать доход с территории.

\section{ЛИТЕРАТУРА}

1. Волков А.Д. и др. Экосистемы ландшафтов запада средней тайги (структура, динамика). Петрозаводск: Карелия, 1990. 284 с.:ил. 
2. Громцев А.Н. Ландшафтные закономерности структуры и динамики среднетаежных сосновых лесов Карелии. Петрозаводск, 1993. 160 с.

3. Моисеев Н.А. Воспроизводство лесных ресурсов. М.: Лесн.пром-ть, 1980. 264 с.
4. Хаггет П. Пространственный анализ в экономической географии: Пер. с англ. М.:Прогресс, 1968 $390 \mathrm{c}$.

5. Koch N.E.and Kenntdy I.I. Multiple use forestry for Sosial Valius. Ambio. 1991. Vol. 20. No.7. P.330-333.

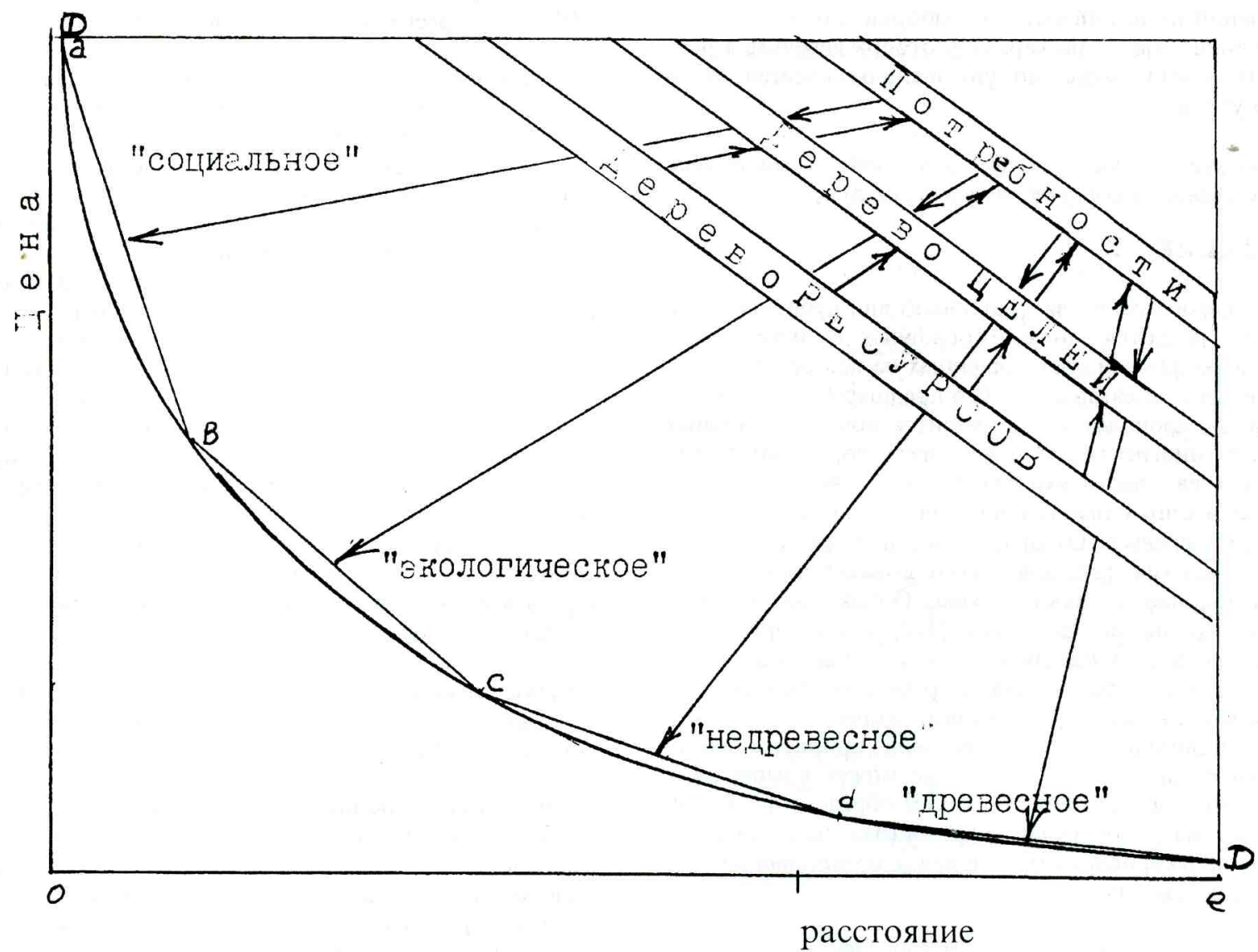

Рис. 1. Возможные направления организации территории в зависимости от расстояния до потребителя 